\title{
La retrocesión de Tarfaya e Ifni
}

\author{
GUADALUPE MONTORO*
}

El uno de enero de 1969, España se incorporaría a su puesto de miembro no permanente del Consejo de Seguridad de las Naciones Unidas -elegida en 1968, por periodo de dos años--, este cargo significaría un triunfo de la política española, largamente perseguida, en la persona del ministro de Asuntos Exteriores Sr. Castiella: de apertura al exterior y reconocimiento internacional al Régimen español. También, y consecuentemente, en 1969 se llevó a feliz término la devolución de lf́ni a Marruecos, tras largas negociaciones en 1968, cuestión que anteriormente había provocado graves situaciones militares y una intensa presión reinvidicadora por parte de Marruecos, sobre todo a partir de 1963.

Con la retrocesión de Ifni, España no había hecho otra cosa que cerrar un proceso que habia intentado prolongar artificialmente, en un marco internacional incompatible con la continuidad de situaciones de este tipo. Por otra parte, en una conyuntura internacional ahora favorable a España, la retrocesión será utilizada como prueba del mantenimiento de la política tradicional de amistad hispano-árabe.

LA CUESTION DE IFNI: 1934-1955

La ocupación de Ifni data del 6 de abril de 1934, a cargo del coronel Capaz ', delegado de Asuntos Indígenas de la Alta Comisaría de España

* Colaboradora del Departamento de Historia Contemporánea de la UNED.

1 Alonso Medrano, M., El General Capaz. Zaragoza, Institución Fernando El Católico, 1958. 
en Marruecos. Esta acción tan tardía, no era más que el cumplimiento del Tratado de Wad-Ras de 26 de abril de $1860^{2}$. Ya que España presionada por Francia, tuvo que proceder a la ocupación efectiva de este territorio, identificado en los Tratados como Santa Cruz de Mar Pequeña, por servir de base para la lucha de los nacionalistas marroquíes allí refugiados, dificultando la pacificación, por parte francesa, de la sona situada entre el Alto Atlas y el Ued Draa.

Esta ocupación fue detectada por la prensa española pero dada la rapidez y lo incruento de la acción, la violenta denuncia anticolonial desplegada por los partidos obreros ante la preparación de los efectivos militares, pronto fue acallada al ser acaparada la atención por el desarrollo de los acontecimientos internos de la Segunda República ${ }^{3}$ - escapándose la circunstancia de que en Marruecos se estaba conformando el principal foco de reacción española en manos de los oficiales africanistas ${ }^{4}$.

Éstos, conocedores de la idiosincracia marroquí, por su larga estancia en Marruecos y convivencia con tropas indigenas, supieron utilizarlos muy eficazmente para la consecución de sus intereses en la Guerra Civil, las relaciones que tenian con las autoridades marroquíes cimentadas a través de a la llamada "política indígena", y canalizar, además, en su provecho el descontento de las formaciones políticas nacionalistas existentes en el Norte del Protectorado, suscitado aquél por la inasistencia de la República a sus reivindicaciones independentistas, adecuando la propaganda y hasta la propia acción a sus fines políticos. Puesto que las promesas hechas por el ejército sublevado representaban una oferta implícita de "autonomía o cierta forma de independencia interdependiente» ${ }^{5}$.

2 El artículo 8, del Tratado establecia: «S.M. Marroquí se obliga a conceder a perpetuidad a S.M. Católica en la Costa del Océano, junto a Santa Cruz de Mar Pequeña, el territorio suficiente para la formación de un establecimiento de pesquería como el que España tuvo allí antiguamente".

Los territorios comprendidos entre los ríos Sus y Dráa fueron vinculados a la Corona de Castilla en 1494, mediante Bula Pontificia. En 1767, por el Tratado de Paz y Comercio, Marruecos reconoce a España el derecho exclusivo de explotación de estos territorios. El Tratado de comercio entre España y Marruecos de 20 de noviembre de 1861, no sólo completará el firmado en 1860, sino que además, ratificará el derecho exclusivo de explotación pesquera otorgado en 1767.

${ }^{3}$ Martin, M., El Colonialismo español en Marruecos. París, Ruedo Ibérico, 1973, pág. 145 y ss.

"Véase, Mas ChaO, Andrés, "La Formación de la Conciencia Africanista". Congreso Internacional de Estrecho de Gibraltar. Ceuta, noviembre 1987. T. III, págs. 331-348.

${ }^{5}$ Gil Grimau, R., "Evolución del pensamiento Africanista español ante la descoloniza- 
El nuevo Régimen inició así un proceso de aperturismo político en Niarruecos tolerando en su territorio la existencia de algunos partidos nacionalistas asi como sus órganos de prensa en lengua árabe, al tiempo que su propaganda, coincidiendo con el período de máximo avance de las potencias del Eje, se orienta hacia la reivindicación del "espacio natural de expansión” en Marruecos a expensas de Francia; pero al terminar la Guerra mundial, truncada la vieja aspiración española, tratará de mantenerse, al menos, como se estaba antes de la contienda y, no obstante no ser España un beligerante, sufrirá de lleno las consecuencias de la aproximación de Occidente a Rusia entre 1941-45. De 1945 a 1947, el Régimen de Franco centrará en si la hostilidad de todos los países del mundo.

El 13 de diciembre de 1946, la Asamblea General de la ONU, tras nueva condena del Régimen español, votaba una moción recomendando a sus miembros la retirada de sus embajadores en Madrid. El aislamiento es entonces casi absoluto y provocará como respuesta, para romper el cerco, lo que se ha venido a llamar "politica de sustitución" " de una intensa política de aproximación al Mundo Árabe e Hispanoamerica, como pilar esencial en la ruptura del aislamiento exterior y la vuelta a la Sociedad Internacional ${ }^{7}$, así como en bastión del anticomunismo occidental a lo largo de los años 50 y 60.

Entre tanto, en julio de 1946, España crea el África Occidental Española (AOE) integrada por Ifni, Tarfaya (o Cabo Juby) y el Sahara (o Río de Oro), se sustituye la dependencia de estos territorios de la Alta Comisaría por la Presidencia de Gobierno, a través de la Dirección General de Marruecos y Colonias, y se unifica el mando en la figura del Gobernador general del AOE. Asimismo, y a tenor de lo estipulado en el Tratado de 1912, se reconoce a Tarfaya como Zona de Protectorado (Protectorado Sur) que queda sometida, a su vez, a la autoridad del Alto Comisario que actúa como delegado ante el Gobernador General.

Esta organización subsistirá hasta 1958, fecha de entrega formal de Tarfaya a Marruecos, cuando el Imperio Xerifiano estuvo en condiciones de hacerse cargo del territorio. A partir de entonces, el AOE estará comprendida por Ifni, que será sede el gobierno del AOE con un delegado

ción del Magreb, durante el periodo 1945-1975". Boletín de la Asociación Española de Orientalistas. 1989.

${ }^{6}$ Moran, F., Una política exterior para España. Barcelona, Planeta, 1980, págs. $142-$ 144.

7 Lisbona Martin, J. A., "La incidencia de la Tradicional Amistad Hispano-Arabe", en La descolonización de las posesiones españolas del Magreb. III Aula Canarias Noroeste de África. Las Palmas, 1988. Coordinado por el Profesor Morales Lezcano (En imprenta). 
gubernativo residente en Sidi Ifni y por el Sahara, con un subgobernador residente en El Aaiún.

Este tipo de administración "no autónoma» ${ }^{8}$, supone un reforzamiento de la presencia española en estos territorios como respuesta al viraje originado por la II Guerra Mundial, que puso de relieve la importancia estratégica del AOE.

En efecto, durante la guerra, el AOE ya habia cobrado especial relevancia en la política defensiva española, no sólo ante la inminente amenaza de desembarco en Canarias por parte de los aliados ${ }^{9}$, sino también, por la utilización de los desiertos como cualquier otro teatro de operaciones, debido a los avances tecnológicos, hizo que España reforzara no sólo la guarnición del archipiélago canario, sino que se procedió a la ocupación militar de la totalidad de estos territorios africanos por medio de una red de puestos estratégicamente ubicados para la defensa de las fronteras, pasando a ser Canarias centro de gravedad de apoyo logístico del AOE y pieza clave en la política defensiva de la zona, fortaleciéndose así el eje Baleares-Estrecho-Canarias.

No obstante, del reconocimiento de la importancia de este enclave en el plan militar defensivo archipelágico, la precariedad económica por la que se atravesaba, la organización militar y las fuerzas alli existentes durante los cuarenta y aún en la década siguiente, se limitaron a lo indispensable para el mantenimiento de una vigilancia suscinta de costas $y$ fronteras y de la acción del Gobierno General ${ }^{10}$.

Esta precariedad de medios se puso en evidencia ante el deterioro de las relaciones entre Francia y Marruecos, agudizada a partir de 1949, tras el discurso del Sultán en Tánger, en donde plantearía abiertamente la necesidad de que Francia diera mayor autonomía a Marruecos. Si bien España utilizó el contencioso Franco-marroquí en provecho de su política exterior ${ }^{11} \mathrm{y}$ de su actuación respecto a su zona de Protectorado, en el

${ }^{8}$ Sobre la negativa por parte de España a informar a la Sociedad Internacional sobre los territorios administrados que no hubiesen alcanzado aún el gobierno propio, véase en PINIES, J., La descolonización del Sáhara: un tema sin concluir. Madrid, Espasa Calpe, 1990, pág. 14.

9 El día 11 de agosto de 1941. Churchill había dado cuenta secretamente de esta decisión al presidente Roosevelt.

La proximidad entre el Archipiélago y el AOE hizo cobrar importancia a estos territorios.

${ }^{10}$ Servicio Histórico Militar (SHM) Ponencia de África. "Estudio Geográfico Militar del Sahara Español», Lg. 1, 1944 fol. 50.

$"$ Lisbona Martin, J. A., ob. cit. 
verano de 1954 las protestas que se produjeron en Tarfaya y que fueron canalizadas por algunos Chiujs, daría lugar al viraje de la actitud marroquí respecto a la presencia de España en su territorio ${ }^{12}$; malestar que sería aprovechado por la intensa propaganda radiofónica que el Istiqlal (Partido de la Independencia y la Constitución) venía ejerciendo desde Marruecos sobre el AOE.

Ante las pretensiones unificadoras marroquies, la valoración que en 1954 hacia el Gobierno General a fin de justificar la conservación en manos españolas del AOE, y descartados los planteamientos de tipo económico - puesto que en aquel período se carecía de infraestructura para hacer rentable la explotación-, era de tipo geográfico y militar, siendo el enclave saharaui el de mayor importancia ${ }^{13}$. pero, una vez descartada la idea, por la evolución de la política internacional, de un ataque de fuerza por parte de Francia, se consideró la situación de Ifni más preocupante.

En efecto, la extraordinaria agitación nacionalista marroquí en los territorios circundantes a sus $125 \mathrm{~km}$ de frontera artificial, hacian prever acciones rápidas desde el exterior por fuerzas incontroladas marroquies ${ }^{14}$. Por otro lado, se temia que la existencia de refugiados procedentes de la represión francesa - aunque su número no fuera muy elevado-soliviantara a la población. Por el contrario, y respecto al Sahara, por estas fechas aún no se temía que se produjeran infiltraciones, en base a las duras circunstancias del desierto que dificultaban la existencia por sí mismos de efectivos incontrolados de importancia, dada la creencia general de que no serian apoyados por los saharauis, porque según se pensaba, a éstos les interesaban más la protección de España para su futura independencia que la anexión por parte de Marruecos ${ }^{15}$.

Asi pues, y en base a planteamientos políticos y militares para el $A O E$, ante al agravamiento de la situación marroquí y las posibles implicaciones que pudieran dar lugar en Ifni y norte del Sahara, el Gobierno de Madrid autoriza a finales de 1955, otra organización y despliegue de fuerzas militares alli radicadas, de acuerdo con el plan defensivo siguiente: Defensa preferente de la zona del Sahara; defender Ifni "a toda cos-

12 Carta del gobernador general al director general de Marruecos de 2 de diciembre de 1954. Cit. en CASAS DE LA VEGa, La última Guerra de Átrica. Madrid, EME, 1985, pág. 42.

13 SHM. (Madrid). Informe del Gobernador general del AOE de 25 de septiembre de 1954. Lg. 1.1954.

14 El 29 de enero de 1954, se habian observado concentraciones lipo Harcas en la zona de Tarudan, a menos de $30 \mathrm{~km}$ de la frontera de Ifni. Véase nota informativa del teniente coronel jefe del E.M., SHM. Lg., 1 (1954).

15 Casas de la Vega, R., ob. cit., pág. 42. 
ta" y defensa móvil del Sahara, y por último, acción retardatriz de ambas zonas y resistencia al máximo en población, puestos y aeródromos ${ }^{16}$.

En este plan defensivo, Ifni pasará a ser considerado el centro de gravedad del despliegue y Canarias centro logístico del AOE ${ }^{17}$. Sin embargo, al tener que ajustarse esta reorganización militar a los presupuestos vigentes, dentro de la línea de austeridad marcada por el Gobierno de Madrid, significaría una solución a medias, al continuar la escasez de hombres y material deficitario como se venía denunciando por las autoridades militares de la zona y que acontecimientos posteriores dejarán al descubierto.

\section{LA INDEPENDENCIA DE TARFAYA Y LA GUERRA DE 1958}

A mediados de 1955, Francia considerando excesivo el coste que le originaba su permanencia en Marruecos cambia totalmente de actitud. El 2 de marzo de 1956, será reconocida la independencia de la zona de Protectorado francés y el 7 de abril, el Gobierno español no tendrán más remedio que secundar la iniciativa francesa, si no quería perder el apoyo, que todavía necesitaba, del grupo árabe en la ONU.

Las negociaciones Hispano-marroquíes enconaron aún más la agitación nacionalista en el mes de abril al extenderse la creencia que en las mismas se incluía todo el $A O E$, realizándose concentraciones en los distintos puntos de Ifni y Tarfaya para festejar su supuesta independencia ${ }^{19}$, y no se pudieron evitar algunos incidentes violentos aislados que incluso afectaron, aunque en menor medida, al Sahara Español ${ }^{20}$.

El Gobierno de Madrid no se dejó arrastrar por los acontecimientos, y se iniciaron una serie de medidas, a excepción de las violentas, con el

${ }^{16}$ SHM. (Madrid) Escrito del jefe del Estado Mayor Central al capitán general de Canarias de 10 de diciembre de 1955. Lg. 1, (1955).

${ }_{17}$ Véase SHM. (Madrid) Lg. 1, carpeta 8 (1954).

${ }^{18}$ SuArez Fernandez, Franco y su tiempo. Madrid, Fundación F. Franco, Tomo V, pág. 198.

${ }^{19}$ Sobre la situación de la zona, véase en SHM. (Madrid) Lg. 2, Carpeta 4, (1956).

${ }^{20}$ Radiograma procedente del El Aaiún del subgobernador al gobernador general de 9 de abril de 1956. Ibidem. 
fin primordial de "ganar tiempo" ${ }^{21}$ y diera lugar a que la explosión independentista se redujera a simple exteriorización de una aspiración y no a un hecho consumado ${ }^{22}$.

Dentro de esta política de tolerancia, se autorizaron las manifestaciones y se permitió al Istiqlal a que estableciera en todos los poblados de Ifni y Cabo Juby oficinas del partido.

En cuanto a los resultados obtenidos con la adopción de medidas de seguridad, en función de la máxima propugnada desde el Gobierno General de "serenidad y tolerancia, respaldadas por la fuerza", en Ifni, poco se lograría en relación con la Administración española por la actitud de animosidad de su población, ya que a excepción de Sidi Ifni, en el campo la población siguió sin aparecer por las Oficinas de Policia que quedaron aisladas del pueblo, y limitada su función al mantenimiento del orden público, al acudir los habitantes a las de Istiqlal y llevar sus pleitos al partido. Actitud calificada de "guerra fría" y que a juicio del Gobernador general de mantenerse "será expuesto a que el buen propósito de no emplear la fuerza tenga su fin» ${ }^{23}$.

La situación se vino a enconar con dos hechos relevantes: la reclamación por Marruecos de los territorios situados desde el Uad Draa al paralelo $2740^{\prime 24}$ y la concentración de Bandas Armadas del Ejército de Liberación (dirigido por Allal El Fassi, quién pretendía construir un Imperio para Marruecos) en el Norte de la frontera marroquí con Cabo Juby. $Y$ ello por estar prevista la "marcha sobre Mauritania», al mando de Ben Hammu, para finales de octubre pasando por el Sahara Español.

La razón que llevó a la autorización del paso de las Bandas Armadas de Liberación, según el Gobernador general, era porque se consideraba menos peligroso mantenerlos continuamente controlados a que el Ejército de Liberación actuase de forma "misteriosa y clandestina» causando con

${ }^{21}$ Escrito del gobernador general al capitán general de Canarias 16 de abril. SHM. (Madrid) Lg. 2, carpeta 5 (1956).

22 ibidem.

${ }^{23}$ Escrito del gobernador general al capitán general de Canarias de 16 de abril de 1956, véase carta que dirige Gómez Zamalloa al ministro del ejército el 3 de agosto de 1957. SHM.: (Madrid) Campaña de Ifni-Sahara. Libro Blanco, t. I..

${ }^{24}$ El 3 de mayo el Sultán recibe una Comisión de autoridades de varios lugares, entre ellos del Sahara español. La noticia fue dada por radio Rabat y en la que textualmente se dice: "continuaré recuperando e incorporando a Marruecos palmo a palmo, todos los terrítorios que to integraban". Cit. telegrama del gobernador general al director general de 4 de mayo de 1956. Ibidem. Sin embargo, no será hasta el 15 de septiembre de 1957, cuando el gobierno de Rabat exprese sus deseos, expuestos verbalmente, de hacerse cargo del Protectorado Sur. 
ello mayor impacto en los saharauis ${ }^{25}$. Por otro lado, esta actuación era consecuente con la política de “Amistad Hipano-árabe" mientras que Francia era tenaz valedora del cerco internacional a España. Sin embargo, las Bandas Armadas comienzan a controlar el territorio. En octubre de 1957, se contabilizan por los servicios de información españoles 3.000 hombres sólo en Río de Oro ${ }^{26}$, que hará que España vea en ellas un peligro para la conservación del territorio y por consiguiente el planteamiento, como única solución viable - a pesar de que se desconfiaba de las intenciones francesas- de cooperación con Francia ${ }^{27}$.

Entre tanto, el Gobierno de Franco había acordado el "Plan Madrid", que comprendía, en síntesis, las siguientes fases: presión diplomática cerca del Gobierno de Rabat; ultimátum a las BAL y acción militar de fuerza ${ }^{28}$, que no pudo desarrollarse ante el ataque por sorpresa a Ifni el 23 de noviembre de 1957. Y aunque en un principio se intentó limitar el alcance del ataque a Ifni, los sucesos posteriores llevarían a cambiar la buena disposición inicial de que Ifni seria objeto de negociación directa a pesar de la situación jurídica, por considerarse que sería «un premio de la agresión” ${ }^{29}$. Por lo que se llegó a la firme decisión de movilizar si fuera preciso cuantos recursos pudieran ser necesarios para defender los derechos sobre Ifni $^{30}$.

Los graves enfrentamientos que se produjeron entre noviembre de 1957 y finales de $1958^{31}$ aceleraron la transferencia de Tarfaya. A primeros de abril de 1958 se celebra la conferencia de Cintra, por la que

${ }^{25}$ Boletín de Información semanal de la Secretaría núm. XXX|X, del 7 de octubre. Lg. 3 (1956).

${ }^{26}$ "Estudio Monográfico sobre las Bandas Armadas de Liberación». SHM. Lg. 9 (1957).

${ }^{27}$ "Relaciones Franco-españolas", Libro Blanco, t. 1., doc. n. 24. Véase, Acta de la conferencia de Dakar. SHM. (Madrid) Lg. 8 (1957)..

${ }_{28}$ "Notas sobre la actuación a seguir con las Partidas del E. L. en el Sahara Español», Libro Blanco. t. I.; véase, doc. núm. 7. Ibidem.

${ }^{29}$ El 21 de agosto de 1957, el Presidente del Consejo de ministros marroquí, Si Bekkai, en comunicación oficial, habia solicitado la incorporación de Ifni a Marruecos. El 11 de septiembre, el señor Castiella le contestaria que no habia inconveniente en que fueran sometidas las diferencias de ambos gobiernos a un organismo internacional. Posteriormente y a petición del Gobierno Marroqui se acordó la negociación directa. Véase, SHM. (Madrid) Lg. 10 (1957), sobre la falta de base jurídica para "ligar lfni a la suerte de Marruecos".

30 Ibidem. "Radio Nacional de España. Referencia del Consejo de Ministros", 7 de diciembre de 1957. Lg. 10.

${ }^{31}$ Para el desarrollo de los acontecimientos, véase CASAS DE LA VEGA, R., ob. cit., véase, Diego AguirRe, R., Historia del Sahara Español: La verdad de una traición. Madrid, Kaydeda, 1988, págs. 298-404. Véase Montoro G., África Occidental Española ante la descolonización de Marruecos (1956-1958). Ill Aula Canarias Noroeste de África, al cuidado de Morales Lezcano, V., (en prensa). 
España cede a Marruecos la zona Sur del Protectorado, transferencia que suscitaría incidentes en relación a la entrega ${ }^{32}$.

Entre tanto, se decide sorprendentemente, de cara a la opinión internacional, la provincialización del $A O E$ que significaría la voluntad española de permanecer, a toda costa, en los territorios africanos ${ }^{33}$ acogiéndose, contra corriente, al modelo seguido por Portugal y por el que se pretendia crear la ficción de que territorios con entidad etnocultural propia eran parte integrante de la metrópoli ${ }^{34}$. Decisión que traeria en el futuro más de un quebradero de cabeza en la política de aproximación a las potencias occidentales, porque el camino iniciado en 1956 era irrenunciable.

Estos acontecimientos no enturbiaron las buenas relaciones entre España y el mundo árabe; sin embargo, a partir de los años sesenta se inicia de nuevo una fuerte campaña reivindicadora marroqui que se mantendría hasta 1967, en un clima de crisis social y política interna en Marruecos -en estado de emergencia desde 1965-. Por otra parte, para España, dentro de la línea de actuación política hacia una mayor "democratización» del régimen con miras a integrarse en la Comunidad Económica Europea (Ley Orgánica de diciembre de 1966 y Ley de Sucesión de julio de 1969), la permanencia en Ifni ya no significaba una afirmación de energía y un problema de prestigio y sí un escollo en el avance de la política exterior del Régimen.

El 4 de enero de 1969 se firmó en Fez el acuerdo de retrocesión de Ifni, aprobado por el pleno de las Cortes de 22 de abril, y el 30 de junio fueron traspasados los poderes a las autoridades marroquies.

Con esta acción España se quedaba con las manos libres para centrar toda su atención en la reivindicación de Gibraltar, línea primordial de la política del señor Castiella que se mantuvo en 1969, y que precisaba del apoyo del Grupo de los países árabes en la ONU, quienes respaldaban la integración de Ifni a Marruecos. Sin embargo, la retrocesión de Ifni no acallaría las pretensiones dovolucionistas. La cuestión del Sahara español afectaría las relaciones de España con Marruecos y Mauritania y pondría de relieve la falta de consistencia de la politica de amistad hispano-árabe asentada de manera formalista durante la dictadura.

\footnotetext{
32 Véase Boletines de Información núms. 15 al 17, mes de abril 1958. SHM. Lg. 12.

33 Yanguas Miravete, J., Antecedentes históricos, organización político-administrativa de las provincias del Ifni y Sahara. Sidi Ifni 1960.

${ }^{34}$ Véase las contribuciones de Morales Lezcano V., Lopez Garcia B. y Maestre Alonso J., sobre: «El fracaso del colonialismo franquista". Historia 16, extra, abril 1979, pág. 128.
} 